\title{
Care of the Newborn in Developing Countries
}

Isaac Oludare Oluwayemi ${ }^{*}$, Ezra Olatunde Ogundare and Oladele Simeon Olatunya

Department of Paediatrics, Faculty of Clinical Sciences, College of Medicine, Ekiti State University, Ado-Ekiti, Nigeria

*Corresponding author: Isaac Oludare Oluwayemi, Department of Paediatrics, Faculty of Clinical Sciences, College of Medicine, Ekiti State University, Ado-Ekiti, Nigeria, Tel: +2348034052636; E-mail: dareoluwayemi@gmail.com

Rec date: 14 Apr, 2014; Acc date: 14 Oct, 2014; Pub date: 16 Oct, 2014

Copyright: (C) 2014 Oluwayemi IO et al. This is an open-access article distributed under the terms of the Creative Commons Attribution License, which permits unrestricted use, distribution, and reproduction in any medium, provided the original author and source are credited.

\begin{abstract}
The newborn period is the most challenging period of human life and it is the period most susceptible to morbidity and mortality. Neonatal morbidity and mortality contribute significantly to infant mortality rate and under-five mortality rate globally; which are important indices for determining the level of development of any country. In most African countries and other developing parts of the world, there are inadequate resources and these reflect on the care given to their newborns. Therefore, there is need to understand the peculiarities, challenges and common problems newborns face in these countries with the aim of providing optimal care for the newborns: the goal of this review.
\end{abstract}

Keywords: Newborn; Care; Congenital; Infection; Mortality

\section{Introduction}

A newborn is defined as a baby within the first twenty-eight days of life. This period is an important time in the life of the baby and the family. The time of birth is a period of transition from the dependent intrauterine life to independent extrauterine life which requires some physiologic and biochemical adjustments in the baby. Immediately after delivery, the physiological systems of the baby must take over the vital functions being sub-served by the placenta during the intrauterine life. Of the many changes that occur after birth, expansion of the lungs and onset of regular respiration are important since some vital bodily functions like blood circulation depend on them. Some newborns navigate this critical period successfully while others do not. The size and level of development of the newborn at birth, the mode of delivery, the metabolic reserve and the capacity to adjust to extrauterine life also are major factors that determine survival of the newborn. The neonatal period is a time during which the infant is highly vulnerable and this is attested to by the high neonatal morbidity and mortality rates. Every year, nearly forty percent of all under-five child deaths occur among newborns [1]. Three quarters of all newborn deaths take place in the first week of life while as much as 25 to 40 percent die within 24 hours of birth [1,2]. The major causes of neonatal mortality include prematurity and low birth weight, birth asphyxia, infections and birth trauma [3]. These account for about 86 percent of neonatal deaths [1]. About $99 \%$ of neonatal deaths occur in developing countries with about $50 \%$ occurring at home [1]. In developing countries, about fifty percent of newborns and their mother do not receive skilled care during and immediately after delivery, [4] for instance in sub-Sahara Africa, less than $40 \%$ of women deliver with skilled care while in south Asia, the figure is less than $30 \%$ [1]. This lack of skilled care probably contributes to the high neonatal mortality rates recorded in most developing countries. Up to two thirds of deaths among newborns in developing countries can be prevented by simple but effective health measures which can be provided during and immediately after birth to enhance the capacity for the needed physiological adjustments [5]. Survival of newborn in developed countries is greatly enhanced by the high level of evidencedbased care given to every newborn and routine screening for some congenital disorders which could compromise the survival of the newborn if not detected and treated early. Screening is done for conditions that are relatively common, and can be treated, even if fatal; examples include screening for hypothyroidism and disorder of sexual development (DSD) among many others [6,7]. Screening for structural abnormalities using non-invasive tools like ultrasound and echocardiogram have also been found useful $[8,9]$. However, many of these screenings opportunities are still elusive and unaffordable to people in the developing countries mainly as a result of inadequate tools, funds and high cost of health care delivery. Also, most deliveries are unattended with more than $60 \%$ of deliveries in Africa taking place outside hospital [10]. Other factors include: early discharge of newborn from hospital after birth, lack of political will from government and multi-faceted administrative bottlenecks. Furthermore, there are insufficient trained personnel like midwives and Pediatricians; in Nigeria for instance, there are only 600 Paediatricians to care for an estimated population of 40 million children [11]. Little wonder that the infant mortality rate and underfive mortality rate was as high as 78/1000 live birth and 124/1000 live births respectively compared to $6 / 1000$ and $8 / 1000$ from the USA respectively [12]. Also, Nigeria together with four other countries (India, Democratic Republic of the Congo, Pakistan and China) account for a third of all the under-five death worldwide [13].

The newborn baby can either be born prematurely/ preterm (delivery before thirty seven completed weeks of pregnancy), at term (delivery between thirty seven completed weeks and forty two weeks of pregnancy), or post term (delivery after forty two weeks of pregnancy). These three groups of newborn have their peculiar features and require appropriate care for survival, optimal growth and development. It is imperative to adequately care for the preterm and low birth weight babies as these conditions are now being implicated as causes of medical problems such as hypertension and increased cardiovascular risk amongst other problems later in life [14].

\section{Appearance and Activities of a Normal Newborn Baby}

A normal human newborn delivered at term weighs between $2500 \mathrm{~g}$ and $4000 \mathrm{~g}$. Babies weighing less than $2500 \mathrm{~g}$ are referred to as Low birth weight (LBW) babies while those weighing more than $4000 \mathrm{~g}$ at 
Page 2 of 6

birth are termed macrosomic babies [15]. Low birth weight may be due to prematurity or intrauterine growth restriction (IUGR). Low birth weight babies have peculiar challenges of maintaining normal body temperature, hypoglycaemia, jaundice, a higher risk of neonatal infections and congenital malformations; hence higher risk of mortality. The macrosomic babies are particularly prone to birth trauma especially if delivered per vagina; they are also prone to hypoglycemia, asphyxia and neonatal jaundice.15 If a newborn is healthy, he or she cries, moves all four limbs, grasps the finger of the caregiver tightly if placed across his/ her palm (grasp reflex), turns the head towards the direction of a finger or breast nipple touching the angle of the mouth (rooting reflex); opens and closes the eyes intermittently; sucks the breast or finger if placed in his/ her mouth (sucking reflex). The umbilical stump is gelatinous, has three visible blood vessels ( 2 arteries and 1 vein); the anus is patent and baby passes greenish colored stool (meconium) within the first day of life; passes urine freely with good stream soon after delivery [16-19]. Two soft boneless, sometimes pulsating, areas are seen/ felt on the head: one on the frontal part of the head (anterior fontanel) and the second one on the posterior part of the head (posterior fontanel). The anterior fontanel closes between 9th and 18th month of age while the posterior fontanel closes between 3rd and 4th month of age [20]. When pulled by the hands to the sitting position, the baby lifts the head momentarily to align with the trunk. Each hand and foot has five fingers and toes respectively.

The baby develops from head to the lower parts of the body; hence, by age 5-6 weeks the baby smiles in response to the mother's smile or playful gestures (social smile); able to hold up his/ her neck and turn the head sideways (neck control) by age 3-4 months; sits without support at 6-7 months; crawls at 6-8 month, stands with support at 8 months; stands without support at 9 months; walks with support at 10-11 months and some walk without support by one year of age [21]. The first tooth of a baby appears at about the 6th month of life followed by one tooth per month, such that for the first two years of life the age of a baby can be roughly estimated by counting the number of teeth in the mouth of the child and adding six months to it. However, variations do exist with some babies born with a tooth (natal tooth) while some will erupt the first tooth in the first month of their extrauterine life (neonatal tooth) and some may not erupt any tooth until after 14 months of life such babies are said to have delayed teething if they are not born as a preterm [22]. Most normal babies will start babbling by the time they're bringing out teeth and by the 12th month start verbalizing one intelligent word usually, "Mama", "Daddy", "water" etc. the vocabulary grows with age [21].

Most babies double their birth weight between 4 and 6 months of life, while the birth weight is tripled at about one year [21]. Average weight at one year is about $10 \mathrm{~kg}$.

\section{Abnormal Features in Newborn}

There are some abnormal features which if found in any newborn should be brought to the attention of Pediatrician. Common ones are going to be highlighted here but it is safe to advice mothers to seek the counsel of those trained in the care of the newborn on whatever appears unusual: it is better to be safe than to be sorry. Listed below are some of these abnormal features that should prompt the mother to present the baby for review:

\section{The head}

- Swelling on the head could be due to bleeding under the scalp (cephal hematoma) which could predispose to severe neonatal jaundice, severe anaemia, bilirubin-induced neurological deficits and cerebral palsy if not attended to promptly and appropriately.

- Cranial synostosis caused by early closure of the sutures and fontanelles, manifesting as a hard non-movable ridge over the suture resulting in the head being abnormally small (microcephaly) and shaped. This may ultimately compromise the development and function of the underlying brain if not treated promptly.

- Soft swelling protruding from any part of the head (encephalocele): protrusion of brain tissue through skull defect

- Unusually big head: this could be a pointer to excessive accumulation of fluid in the brain (hydrocephalus). Needs to be investigated and treated by specialist to allow the child achieve maximum development

- Yellowish discoloration of the eyes (Jaundice)

- Eye discharge (Ophthalmia neonatorum)

- Whitish substance in the centre of the eye (congenital catarract)

- Cleft lips/ palate

- Natal tooth

- Bluish discoloration of the lips, tongue and extremities (cyanosis): suggesting possible congenital heart disease

- Deformities of the pinnae may be seen occasionally as well as preauricular tags which may be unilateral or bilateral

- Ear discharge

- Bloody or milky discharge from the nose

- Congenital torticollis causing the head to turn toward with the face turning away from the affected side

\section{The limbs}

- Abnormally short or long limbs

- Fused fingers and/ or toes (syndactyl)

- Reduced activity or lack of movement in any limb

- Swelling, deformity and pain in any of the limbs (could be due to underlying fracture)

- Extra fingers/ toes (polydactyl)

\section{The chest}

- Difficulty in breathing

- Chest in drawing

- Rapid chest movement

- Abnormal sound from the chest (murmur, wheezing, etc)

- Visible excessive activity of the heart on the left side of the chest wall

- Swollen and painful breasts

\section{The abdomen and back}

- Jelly-like mass or protrusion of internal organs through the umbilical stump (omphalocele)

- Bleeding from the umbilical stump ( poorly ligated cord or hemorrhagic disease of newborn)

- Abdominal distension at birth or shortly afterwards suggests either obstruction or perforation of the gastrointestinal tract 
- A scaphoid abdomen in a newborn suggests diaphragmatic hernia

- Abdominal distension and non passage of stool (could be a pointer to hirschsprung's disease)

- Swelling in any part of the abdomen

- Genitalia neither appearing fully male nor female (ambiguous genitalia)

- Undescended testes

- Imperforate anus

- Penile shaft of a newborn appearing as if it has been circumcised (could be due to hypospadias; please do not circumcise before reporting to specialist who will use the remaining foreskin to repair the defect)

- Difficulty in passing urine, scanty urine or dribbling of urine in addition to fullness or distension of the suprapubic region and irritability may suggest posterior urethral valve

- Ulcer, fleshy protrusion, tuft of hair, a swelling on the lower back (spinal bifida)

- A huge mass on the lower back suggestive of Sacrococcygeal teratoma

\section{The skin}

- Hyperpigmentation of skin and scrotum (congenital adrenal hyperplasia)

- Skin rash especially those containing milky secretions (pustules)

- Redness and swelling in any part of the body

- Bleeding under or on the surface of the skin

\section{General}

- Irritability or inconsolable cry

- Refusal to suck

- Fever

- Palor

- Jaundice

- Vomiting

- Low birth weight (birth weight less than $2.5 \mathrm{~kg}$ )

- Birth weight greater than $4 \mathrm{~kg}$ (macrosomic baby)

- Convulsion

- Delay in initiating regular breathing and activities after delivery (perinatal asphyxia)

- Anything that appears 'strange', 'unusual', 'mysterious' is begging for explanation!

\section{Current Approach to Newborn Care}

In recognition of the link between the health of the mother and that of the unborn child, emphasis is now being placed on both the mother and the fetus and this is referred to as continuum of care, consisting of four interwoven phases that are germane to the health and care received by a newborn baby. These are: (a) Pre-pregnancy care (b) Focused antenatal care (c) Intra-partum care (d) Postnatal care/ care at birth $[22,23]$.

\section{Pre-pregnancy Care}

These are cares given to women of reproductive age group with the aim of preparing them adequately for child birth and its attendant responsibilities. These include female education and empowerment to prevent teenage pregnancy and some harmful cultural practices like female genital mutilation [22,24]. Key components of pre-pregnancy care include provision of good family planning services, nutrition services including micronutrients supplementation, maternal immunization and prevention of sexually transmitted and other congenital infections $[25,26]$. Sadly some of these services are grossly lacking or underutilized in developing countries [27,28].

\section{Focused antenatal Care}

This concept was introduced with the aim of having a more result oriented antenatal care especially in resource poor countries of the world. The design was to ensure that pregnant women in these countries pay at least 4 visits to health facility during each pregnancy and as such has enough interfaces with skilled care givers; such that any identified health problems are nipped in the bud and all are given appropriate immunization alongside prophylaxis against malaria [22]. They are to also receive enough birth preparedness training and child care education during these visits and those completing all the four visits are given some token as incentives [22]. Despite the adoption of this method of antenatal care in Nigeria, recent findings suggest that only $58 \%$ of the country's population of pregnant women attends antenatal care at least once [22]. This is an indication of the low rate of quality antenatal care in the country and this will obviously reflect on the health of their newborn babies.

\section{Intrapartum care}

This involves care given during labour to pregnant women and its success largely depends on the availability of skilled birth attendants, newborn resuscitation care and availability of emergency obstetrics services [29].

\section{Newborn and other postnatal cares}

About $90 \%$ of newborns cry immediately after delivery; have vigorous activity and suffer no complication [30]. About 5 to $10 \%$ require some measure of assistance to establish spontaneous respiration while about $1 \%$ needs extensive resuscitation at birth [30]. The need to assist the newborn is most often assessed using the Apgar score which is assessed at birth and again at the fifth minute of life, however other methods are available. A score of 10 indicates a perfect newborn baby. About $90 \%$ of babies score between 7 and 10; a score of less than 5 requires prompt action [31]. The urgent need at birth for every newborn is to check for difficulty with breathing or other problems. If there is none, the baby is wiped dry to reduce heat loss and wrapped in a warm towel and then handed over to the mother or nursed skin-to-skin beside the mother covered with dry linen [31]. The baby can be put to breast at this point in time. The immediate needs of every newborn at birth are to establish respiration, obtain adequate nutrition, maintain normal body temperature and avoid contact with infection [31]. Majority of neonatal problems arise from failure of physiological adjustments, presence of congenital malformations, maternal infections and illnesses, sepsis and effects of physical or biochemical injury suffered at birth [31].

Immediately after birth, the mouth should be cleaned out of any fluid, blood or excess mucus and thereafter the oropharynx suctioned with a mucus extractor if need be. The umbilical cord should not be cut in a hurry as delayed cord clamping is now being encouraged [32]. Delaying cord clamping for about 1-2 minutes or until the cord pulsation ceases and cutting afterwards in otherwise well term 
Page 4 of 6

newborns may give the baby extra $20-40 \mathrm{mls}$ of blood and about $30-35 \mathrm{mg}$ of iron, thereby protecting the baby from the risk of anemia later in infancy [32]. Also the use of chlorhexidine wash is also being advocated for cord care [33]. The number of vessels in the umbilical cord should be noted as the presence of a single umbilical artery may be associated with some congenital malformations e.g renal artery stenosis [31].

As soon after birth as possible, and within 24 hours of birth, the newborn baby should undergo a detailed clinical examination [33]. The goal of the detailed examination is to:

- To detect congenital abnormalities, if any.

- To ascertain that the baby has withstood the birth process without suffering any injury such as excessive moulding, cephal hematoma, nerve palsies, or fractures.

- To look for signs and symptoms of problems peculiar to the newborn period, such as respiratory difficulties, vomiting, abdominal distension, change in skin colour, or seizures.

The weight, length and head circumference should be documented if the facilities are available as most deliveries in developing countries take place at home.

The baby should be put to breast within the first hours after delivery except if there are contraindications to breastfeeding which may include prematurity (especially babies $<33$ weeks gestation), respiratory distress, persistent vomiting, babies that appear pale or blue, congenital malformations like cleft anomalies, maternal illness and drugs. Such babies may require initial resuscitation and parenteral alimentation prior to when they will be fit to suckle directly from the breast.

Prevention of cold stress after delivery is very essential because newborn infants are at risk for hypothermia. The body surface area of a newborn is approximately three times that of an adult. Also, because the subcutaneous fat layer of the newborn is thinner than that of adult, the estimated rate of heat loss in a newborn is about four times that of an adult [33]. Hence, the newborn needs to be dried up, dressed, wrapped in towel or flannel and handed over to the mother. Under the usual delivery room setting, the newborn infant cumulatively loses about 2-30C of his/her core body temperature if the above measures are not taken promptly [33]. Babies that require to be nursed naked for observation will require a radiant heater or an incubator to keep warm. Preterm or low birth weight babies in resource poor countries where there are not enough incubators or where electricity supply is not regular will benefit from Kangaroo-mother-care. This method of skinto-skin contact care was first developed in Columbia [31]. Since its invention, Kangaroo-mother-care has received endorsements by international bodies and has been used to nurse preterms and low birth babies in many Low income countries with success [34,35]. It serves as a readily available alternative to the more expensive in-ward incubator care for these group of babies by providing good body temperature control through the warmth provided by the mother's skin and also encourages better observation, nutrition and infection control for the low birth weight infant who should have been hospitalized in the usually crowded, ill equipped hospitals in developing countries most of these health facilities are often inadequately staffed [35].

All babies should be given intramuscular injection of Vitamin K1 immediately after delivery to protect against the development of hemorrhagic disease of newborn, $1 \mathrm{mg}$ for babies weighing $\geq 1.5 \mathrm{~kg}$ and $0.5 \mathrm{mg}$ for $<1.5 \mathrm{~kg}$ babies.

\begin{tabular}{|c|c|c|}
\hline Author & Year & Main findings \\
\hline \multicolumn{3}{|c|}{ Neonatal mortality and causes } \\
\hline $\begin{array}{l}\text { Lawn JE } \\
\text { et al., }\end{array}$ & $\begin{array}{l}\text { Lancet, } \\
2005\end{array}$ & $\begin{array}{l}4 \text { million neonates die annually worldwide, three-quarter } \\
\text { of them die within the first week of life and almost all the } \\
\text { deaths occur in low and middle income countries. } \\
\text { The main causes of neonatal death are preterm birth } \\
(28 \%) \text {, severe infections }(26 \%) \text {, asphyxia }(23 \%) \text { and } \\
\text { neonatal tetanus }(7 \%)\end{array}$ \\
\hline \multicolumn{3}{|c|}{ Link between maternal and newborn health } \\
\hline $\begin{array}{l}\text { Zupan } \\
\text { J, } \\
\text { Aahman } \\
\text { E }\end{array}$ & $\begin{array}{l}\text { WHO, } \\
2005\end{array}$ & $\begin{array}{l}\text { Newborn deaths are closely related to the health of the } \\
\text { mother: Teenage pregnancy, lack of skilled attendance at } \\
\text { delivery and postpartum care, maternal malnutrition result } \\
\text { in premature and low birth weight deliveries. }\end{array}$ \\
\hline $\begin{array}{l}\text { Eregie } \\
\mathrm{CO}\end{array}$ & $\begin{array}{lr}\text { East } & \text { Afr } \\
\text { Med } & \mathrm{J}, \\
1993 & \end{array}$ & $\begin{array}{l}\text { Lack of antenatal care, poor maternal immunization and } \\
\text { unsupervised deliveries are associated with poor newborn } \\
\text { outcome }\end{array}$ \\
\hline $\begin{array}{l}\text { Banks E } \\
\text { et al }\end{array}$ & $\begin{array}{l}\text { Lancet, } \\
2006\end{array}$ & $\begin{array}{l}\text { Female genital mutilation leads to obstetrics } \\
\text { complications and difficult deliveries with attendant risks } \\
\text { to newborn health }\end{array}$ \\
\hline $\begin{array}{l}\text { Rutstein } \\
\text { SO }\end{array}$ & $\begin{array}{l}\text { Int J J } \\
\text { Gynaeco } \\
\text { I Obstet, } \\
2005\end{array}$ & $\begin{array}{l}\text { Increasing birth interval is associated with improved } \\
\text { neonatal survival }\end{array}$ \\
\hline $\begin{array}{l}\text { Black } \\
\text { RE et al }\end{array}$ & $\begin{array}{l}\text { Lancet, } \\
2008\end{array}$ & $\begin{array}{l}\text { Maternal under nutrition is highly prevalent in low and } \\
\text { middle income countries with attendant health } \\
\text { consequences on newborns and older children }\end{array}$ \\
\hline \multicolumn{3}{|c|}{ Strategies to reduce newborn deaths } \\
\hline $\begin{array}{l}\text { Kerber } \\
\text { KJ et al }\end{array}$ & $\begin{array}{l}\text { Lancet, } \\
2007\end{array}$ & $\begin{array}{l}\text { The study highlighted packages that can improve } \\
\text { maternal health and newborn survival. These include } \\
\text { paying attention to reproductive health, antenatal care, } \\
\text { postnatal care, care of sick newborn babies, improving } \\
\text { child health services and integrated family and community } \\
\text { care. }\end{array}$ \\
\hline $\begin{array}{l}\text { Ekure et } \\
\text { al }\end{array}$ & $\begin{array}{l}\text { Niger J } \\
\text { Paed, } \\
2013\end{array}$ & $\begin{array}{l}\text { The study revealed inadequate number and uneven } \\
\text { distribution of paediatricians in Nigeria and recommended } \\
\text { training of more paediatricians as well as their even } \\
\text { distribution. }\end{array}$ \\
\hline $\begin{array}{l}\text { Hofmeyr } \\
\text { GA et al }\end{array}$ & $\begin{array}{l}\text { Int J J } \\
\text { Gynaeco } \\
\text { I. Obstet, } \\
2009\end{array}$ & $\begin{array}{l}\text { The study highlighted the fact that some of the } \\
\text { interventions used in developed countries are not } \\
\text { effective in less developed countries. It therefore } \\
\text { recommended investment in health infrastructure, } \\
\text { personnel and research as ways of improving newborn } \\
\text { survival in low income countries. }\end{array}$ \\
\hline $\begin{array}{l}\text { Lawn JE } \\
\text { et al }\end{array}$ & $\begin{array}{l}\text { Int. J. } \\
\text { Epidemi } \\
\text { ol, } 2010\end{array}$ & $\begin{array}{l}\text { Despite the proven benefits of Kangaroo mother care in } \\
\text { significantly reducing mortality among preterm babies, yet } \\
\text { it's still underutilized in low income countries. }\end{array}$ \\
\hline Ibe et al & $\begin{array}{l}\text { Ann Trop } \\
\text { Paediatr, } \\
2004\end{array}$ & $\begin{array}{l}\text { The study established the acceptability of Kangaroo } \\
\text { mother care by Nigerian nursing mothers and the babies } \\
\text { had less risk of hypothermia. }\end{array}$ \\
\hline
\end{tabular}

Table 1: Summary of key findings from some of the studies considered

The mother and the normal baby should leave the labour ward together to promote mother-infant bonding and also to ensure good lactation by the mother. The mother of the baby should be counselled on breastfeeding, cord care, immunization, general hygiene principles and other infection prevention practices before discharge. Mothers should also be counselled on danger signs to watch out for in the baby after discharge and the need to re-present in the hospital if any of these 
Page 5 of 6

signs is noticed. These may include: poor suck, jaundice, excessive stooling, vomiting, fever or hypothermia, abdominal distension, convulsion, bleeding, cyanosis, pallor, difficulty with breathing amongst others.

Home visits by a skilled health worker immediately after birth is a health strategy that can increase newborn survival rates. The strategy has shown positive results in high mortality settings by reducing newborn deaths and improving key newborn care practices [36,37]. While home births are very common in developing countries, only $13 \%$ of women in these countries receive postnatal care in the first 24 hours [36]. Majority of mothers who give birth in health facilities do not return for postnatal care because of financial, social or other barriers. The first days of life are the most critical for newborn survival. Home care visits should occur on days one and three of a newborn's life, and if possible, a third visit should take place before the end of the first week of life (day seven) [36,37]. This is however not practiced in many developing countries like Nigeria, hence the high neonatal mortality [22,37]. Once delivered, the baby should be cleaned up, clothed and put to breast within the first thirty minutes of life. As the baby sucks he takes the first immunization and nutrition from breast milk (the colostrum). Babies should be fed on demand averagely eight times a day i.e. every two to three hours. The baby's weight drops by about 10 to $15 \%$ initially in the first week of life because of the excretion of excess extravascular fluid and reduced nutritional intake. Thereafter the baby regains or exceeds his or her birth weight by the second week of life and is expected to grow at a rate of 20-30grams per day [21]. Breast milk is the preferred food for all categories of newborn, hence mothers should be encouraged to breastfeed their babies. No extra fluid in the first four to six months of life (exclusive breast feeding). The breast milk is the best bio-available food for human babies. The milk is available at the right temperature and could be served by the mother in any convenient posture for both mother and baby any time of the day and anywhere in the universe. Babies who are exclusively breastfed are not likely to develop allergic problems; they are also protected against respiratory tract infections and acute diarrhea diseases. Some mothers often complain about their babies not passing stool for three to four consecutive days sometimes; such mothers should be counselled and assured not to worry if the baby is making urine, active, is not vomiting and has no abdominal distension and is growing well. It only shows that the baby is enjoying and effectively utilizing the breast milk for growth and there is nothing to waste. Apart from food, babies need warmth and this is readily provided by direct contact with the mothers' skin during breast feeding.

Immunization is very essential for adequate protection of babies against certain killer diseases and this should begin at birth. The immunization schedule is regularly reviewed in different countries to adequately protect against childhood killer diseases. Every baby should complete the immunization schedule; prevention is better than cure. The vaccines are very expensive if they were to be purchased by individual parents for their children; hence various supporting international and national non-governmental organizations now subsidize these vaccines and make them available freely for children in the developing world. Despite this approach the vaccination coverage in some of these countries is still low [12]. The table above highlights the findings from some of the articles considered in the review.

\section{Conclusion}

In response to the high neonatal morbidity and mortality in the developing world, the World Health Organization (WHO) came up with some intervention programs, some of which have already been discussed. There is the need to stress the following specific interventions which are focused antenatal and emergency obstetrics care, integrated maternal and newborn health (IMNH), home visits, breastfeeding, immunization and essential drug policy. While some developing countries are keying into these interventions, the situation in other developing countries still need to be addressed. For example, in Nigeria; focused antenatal care, IMNH and home care visits are currently being given attention but these efforts are largely hampered by lack of adequate manpower, funds, corruption and political will [4]. These measures have proven not only to be efficient but also cost effective and suitable for the situations in these developing countries [12]. If the above highlighted measures can be adopted by the developing countries, it will go a long way in reducing the currently prevalent high neonatal morbidity and mortality, thus helping to inch towards attaining the MDG 4 which presently looks like a mission impossible.

\section{References}

1. Lawn JE1, Cousens S, Zupan J; Lancet Neonatal Survival Steering Team (2005) 4 million neonatal deaths: when? Where? Why? Lancet 365: 891-900.

2. Zupan J, Aahman E (2005) Perinatal mortality for the year 2000: estimates developed by WHO. Geneva: World Health Organization.

3. Bang A, Reddy MH, Deshmukh MD (2002) Child mortality in Maharashtra. Economic Political Weekly 37: 4947-4965

4. UNICEF (2000) State of the world's children report 2001. New York: UNICEF.

5. WHO (2012) Newborn: Reducing mortality.Costello AM (1993) Perinatal health in developing countries. Trans R Soc Trop Med Hyg 87: $1-2$.

6. Costello AM (1993) Perinatal health in developing countries.Trans R Soc Trop Med Hyg 87: 1-2.

7. Adeniran KA, Okolo AA, Onyiriuka AN (2010) Thyroid profile of term appropriate for gestational age neonates in Nigeria: a forerunner to screening for congenital hypothyroidism.J Trop Pediatr 56: 329-332.

8. Ciccone MM, Scicchitano P, Salerno C, Gesualdo M, Fornarelli F, et al. (2013) Aorta structural alterations in term neonates: the role of birth and maternal characteristics.Biomed Res Int 2013: 459168.

9. Ciccone MM, Scicchitano P, Zito A, Gesualdo M, Sassara M, et al. (2011) Different functional cardiac characteristics observed in term/preterm neonates by echocardiography and tissue doppler imaging.Early Hum Dev 87: 555-558.

10. Eregie CO (1993) Epidemiological factors associated with neonatal tetanus mortality: observations from a cluster survey in Nigeria.East Afr Med J 70: 434-437.

11. Ekure EN, Esezobor CI, Balogun MR, Woo JG, Mukhtar-Yola M, et al. (2013) Pediatrician workforce in Nigeria and impact on child health. Niger J Paed 40: 112 -118.

12. Children with disabilities (2013) The State of the World's Children 2013.

13. UN Inter-agency Group for Child Mortality Estimation (2011) Levels and trends in child mortality.

14. Mercuro G, Bassareo PP, Flore G, Fanos V, Dentamaro I, et al. (2013) Prematurity and low weight at birth as new conditions predisposing to an increased cardiovascular risk.Eur J Prev Cardiol 20: 357-367.

15. World Health Organization (1992) International statistical classification of diseases and related health problems, tenth revision, World Health Organization, Geneva, 1992. 
16. Loening-Baucke V, Kimura $\mathrm{K}$ (1999) Failure to pass meconium: diagnosing neonatal intestinal obstruction.Am Fam Physician 60: 2043-2050.

17. Clark DA (1977) Times of first void and first stool in 500 newborns.Pediatrics 60: 457-459.

18. Ameh N, Ameh EA (2009) Timing of passage of first meconium and stooling pattern in normal Nigerian newborns.Ann Trop Paediatr 29: 129-133.

19. Weaver LT, Lucas A (1993) Development of bowel habit in preterm infants.Arch Dis Child 68: 317-320.

20. Haslam R (2004) The nervous system. In: Kliegman RM, Behrman RE, Jenson HB, Stanton BF, Nelson Textbook of Pediatrics, 18th ed. Philadelphia, PA: Saunders:2434-2435.

21. Feigelman S (2011) The First Year. In Kliegman RM, Stanton BF, St Geme JW, Schor NF, Behrman RE, eds. Nelson Textbook of Pediatrics, 19th ed. Philadelphia: Elsevier Saunders, 2011.

22. Saving Newborn Lives in Nigeria (2011) Newborn Health in the context of the Integrated Maternal, Newborn and Child Health Strategy. Revised 2nd edition, Federal Republic of Nigeria Ministry of Health 2011.

23. Kerber KJ, de Graft-Johnson JE, Bhutta ZA, Okong P, Starrs A, et al. (2007) Continuum of care for maternal, newborn, and child health: from slogan to service delivery.Lancet 370: 1358-1369.

24. Banks E, Meirik O, Farley T, Akande O, et al. (2006) Female genital mutilation and obstetric outcome: WHO collaborative prospective study in six African countries.Lancet 367: 1835-1841.

25. Rutstein SO (2005) Effects of preceding birth intervals on neonatal, infant and under-five years mortality and nutritional status in developing countries: evidence from the demographic and health surveys.Int J Gynaecol Obstet 89 Suppl 1: S7-24.

26. Black RE, Allen LH, Bhutta ZA, Caulfield LE, de Onis M, et al. (2008) Maternal and child undernutrition: global and regional exposures and health consequences.Lancet 371: 243-260.

27. Hofmeyr GJ, Haws RA, Bergström S, Lee AC, Okong P, et al. (2009) Obstetric care in low-resource settings: what, who, and how to overcome challenges to scale up?Int J Gynaecol Obstet 107 Suppl 1: S21-44, S44-5.
28. Galadanci HS, Ejembi CL, Iliyasu Z, Alagh B, Umar US (2007) Maternal health in Northern Nigeria: a far cry from ideal.BJOG 114: 448-452.

29. Wall SN, Lee AC, Niermeyer S, English M, Keenan WJ, et al. (2009) Neonatal resuscitation in low-resource settings: what, who, and how to overcome challenges to scale up?Int J Gynaecol Obstet 107 Suppl 1: S47-62, S63-4.

30. Barber CA, Wyckoff MH (2006) Use and efficacy of endotracheal versus intravenous epinephrine during neonatal cardiopulmonary resuscitation in the delivery room. Pediatrics 118: 1028 -1034.

31. Sinkiss D, Edmund K, Waterson AJ, Bose A, Troy S et al. Care of the Newborn in Developing Countries. chapter 6: 67-79.

32. Maheshwari A, Carlo WA (2011) Anemia in the newborn infant. In Kliegman RM, Stanton BF, St Geme JW, Schor NF, Behrman RE, eds. Nelson Textbook of Pediatrics. 19th ed. Philadelphia: Elsevier Saunders.

33. Carlo WA (2011) The Newborn infant. In Kliegman RM, Stanton BF, St Geme JW, Schor NF, Behrman RE, eds. Nelson Textbook of Pediatrics. 19th ed. Philadelphia: Elsevier Saunders.

34. Lawn JE, Mwansa- Kambafwile J, Horta BL, Barros FC, Cousens S (2010) 'Kangaroo mother care to prevent neonatal deaths due to preterm birth complications. Internal Journal of Epidemiolgy: 1-10.

35. Ibe OE, Austin T, Sullivan K, Fabanwo O, Disu E, et al. (2004) A comparison of kangaroo mother care and conventional incubator care for thermal regulationof infants $<2000 \mathrm{~g}$ in Nigeria using continuous ambulatory temperature monitoring. Ann Trop Paediatr 24: 245- 251.

36. WHO, UNICEF, USAID (2009) Children St. WHO -UNICEF Joint statement on home visits for the newborn child; a strategy to improve survival.WHO, Geneva.

37. Baqui AH, Ahmed S, El Arifeen S, Darmstadt GL, Rosecrans AM, et al. (2009) Effect of timing of first postnatal care home visit on neonatal mortality in Bangladesh: a observational cohort study.BMJ 339: 2826. 